\title{
Comparison of bismuth citrate and 5-aminosalicylic acid enemas in distal ulcerative colitis: a controlled trial
}

\author{
R D Pullan, S Ganesh, V Mani, J Morris, B K Evans, G T Williams, J Rhodes
}

\begin{abstract}
An enema that contained a complex of bismuth citrate and polyacrylate was compared with 5-aminosalicylic acid (5-ASA) enemas for treatment of distal ulcerative colitis. The multicentre trial involving 63 patients was randomised and double blind with enemas given over four weeks; clinical, sigmoidoscopic, and histological assessments were made. Improvements were seen in both treatment groups. Clinical remission was seen in 18 of 32 patients treated with 5-ASA and 12 of 31 patients treated with bismuth citratecarbomer $\left(\chi^{2} 1.94 ; p=0 \cdot 16\right)$. Sigmoidoscopic remission occurred in 20 of 32 patients in the 5-ASA group and 15 of 31 patients given bismuth $\left(\chi^{2} 1.27 ; p=0.26\right)$. Improvement of rectal biopsy histology by at least one grade was seen in 16 of 32 patients in the 5-ASA group and 14 of 31 patients with bismuth $\left(\chi^{2}\right.$ $0 \cdot 15 ; p=0 \cdot 70)$. Analysis of covariance gave no significant difference between groups, although there was a trend favouring 5-ASA. There was no evidence of bismuth accumulation during the trial. Bismuth enemas may offer a new therapeutic option in distal ulcerative colitis.
\end{abstract}

(Gut 1993; 34: 676-679)

Department of Gastroenterology R D Pullan J Rhodes

Department of Pathology, University Hospital of Wales, Cardiff

G T Williams

Department of Gastroenterology, Leigh Infirmary, The Avenue, Leigh, Greater

Manchester

$S$ Ganesh

V Mani

Department of Medicine, Princess of Wales Hospital, Bridgend, Mid-Glamorgan $\mathrm{J}$ Morris

The Pharmaceutical Unit, St Mary's Hospital, Corbett Road, Llandough, Cardiff B K Evans

Correspondence to: Mr R D Pullan, FRCS Department of Gastroenterology, University Hospital of Wales, Heath Park, Cardiff CF4 4XW Accepted for publication 6 October 1992 In recent years enemas of 5-aminosalicylic acid (5-ASA) have proved effective for treatment of distal ulcerative colitis ${ }^{12}$ and results have been comparable with those from steroid enemas. ${ }^{34}$ In the course of trying to identify therapeutic agents for this disease two recent studies have shown benefit with bismuth preparations. ${ }^{56}$ Encouraged by these findings we have formulated a bismuth enema and compared it with 5-ASA enemas in patients with active distal colitis to examine the therapeutic effect.

\section{Methods}

Sixty eight patients with active left sided ulcerative colitis were identified from gastroenterology outpatients in three centres and randomly allocated to receive either 5-ASA enemas ( $2 \mathrm{~g}$ 5 -aminosalicylic acid in $100 \mathrm{ml}$ ) or bismuthcitrate-carbomer enemas. The bismuth enemas contained $450 \mathrm{mg}$ bismuth citrate, equivalent to $216 \mathrm{mg}$ of metallic bismuth with $900 \mathrm{mg}$ carbomer 934P (Carbopol, Goodrich Ltd, UK) in $100 \mathrm{ml}$ with a $\mathrm{pH}$ of 6.5 to $7 \cdot 4$. Patients were instructed to administer the enema once daily before retiring to bed and were warned that they may pass dark stools as a result of treatment.

All had either a rigid or flexible sigmoido- scopic examination and where the upper limit was not identified, extent of disease was established by barium enema or colonoscopy.

Exclusion criteria were the presence of enteric infection on stool culture, inability to retain enemas for at least one hour, hypersensitivity to aminosalicylates, pregnancy or lactation, and use of steroid enemas in the previous two weeks. The patients' usual dose of other medications taken for colitis such as oral mesalazine, olsalazine, sulphasalazine, and corticosteroids taken in the previous month remained unchanged throughout the trial.

Clinical, sigmoidoscopic, biopsy, haematological, and biochemical assessments were made at the beginning and end of the four week trial period or when patients were withdrawn prematurely.

Serum bismuth concentration was measured initially and after two and four weeks with samples taken 12 to 16 hours after enema administration.

Symptoms were assessed in terms of general health, and the number of stools passed each day, with a note of their consistency and the presence of blood and mucus in the stool. The occurrence of abdominal pain, anorexia, nausea, and any systemic complications of colitis were noted. The symptoms were combined with the sigmoidoscopic findings to give a 'St Mark's score'. ${ }^{78}$

A diary card was kept during the trial to record stool frequency, its consistency, and the presence of blood and mucus. General wellbeing and urgency were also recorded by a scoring system; wellbeing was scored 1 to 10 (poor to very well) and urgency from 1 to 10 (none to severe). An overall clinical global grade was given according to Truelove and Witts (Table I). ${ }^{9}$ At the end of the study patients were asked whether they found the enemas acceptable or whether they had encountered difficulty in their administration.

The severity of inflammatory change was graded visually at sigmoidoscopy with a scale devised by Baron et al (Table I). ${ }^{10} \mathrm{~A}$ biopsy was taken $8 \mathrm{~cm}$ from the anal margin on the anterior rectal wall; these were subsequently examined histologically to assess inflammatory activity, which was graded in a standard manner (Table I). ${ }^{11}$

All assessments were made without knowledge of the treatment group.

\section{STATISTICAL TESTS}

Characteristics of the two treatment groups at entry were compared with the unpaired $t$ test and $\chi^{2}$ test for the sex ratio. The paired $t$ test was used 
TABLE I Grading schemes used for assessments

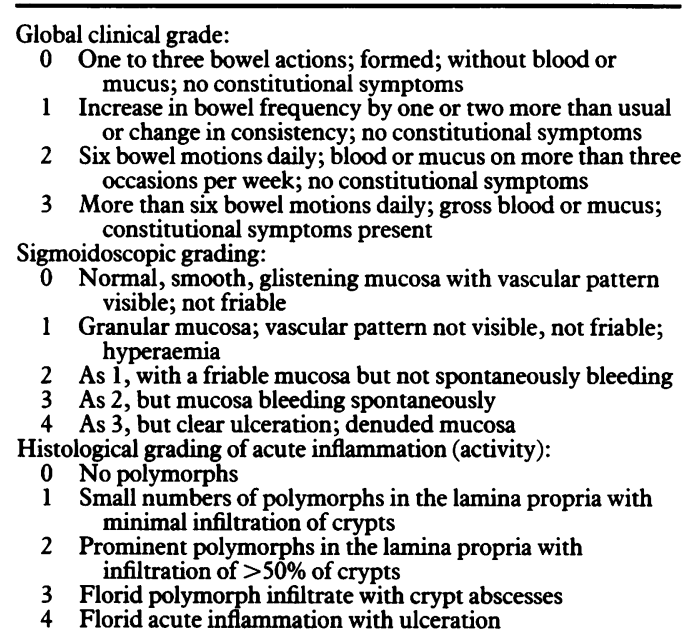

Overall clinical grade of the severity of colitis according to Truelove and Witts ${ }^{9}$ by which patients were graded at the beginning and end of the trial period. The sigmoidoscopic grade at the beginning and end of the trial was derived from Baron et al. ${ }^{10}$ Histological grades for rectal biopsies taken $8 \mathrm{~cm}$ from the anal verge were based on Truelove and Richards. ${ }^{11}$

to examine changes over the trial period within each group. As the two treatment groups were not identical in severity of disease at the start of the trial, an analysis of covariance, with corresponding confidence intervals, was used to compare each measure between the groups after treatment, making adjustments for the differences in severity of disease before treatment as measured by the corresponding baseline measurement. The $\chi^{2}$ test was also used for proportions exhibiting specified changes.

\section{Results}

Although 68 patients were admitted to the trial five were subsequently withdrawn from further analysis. Three of these had discontinued treatment themselves after only a few days and failed to keep further appointments, one was found to have severe total colonic disease on colonoscopy, and one was found to have Crohn's disease; none of these five patients had side effects from treatment and were deemed unsuitable for analysis. Of the three who discontinued their own treatment one had multiinfarct dementia and the other two, contacted by phone, had improved but did not wish to take further part in the study. Of the remaining 63 patients six were withdrawn before the end of the trial period for reasons given in Table II. The subsequent analyses are based on the principle of intention to treat,

TABLE II Details of patients withdrawing from treatment prematurely

\begin{tabular}{ll}
\hline Reason for withdrawal & Treatment group \\
\hline Patient request - failure to improve & 5-ASA \\
Patient request - failure to improve` & Bismuth \\
Withdrawn - clinical deterioration & Bismuth \\
Unable to tolerate enemas & 5-ASA \\
Patient request - difficulty retaining & 5-ASA \\
Unable to use enemas - pain & Bismuth \\
\hline
\end{tabular}

Details of the six patients withdrawn from the trial because of difficulties related to treatment.

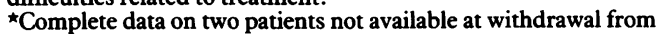
the trial. applied to the total group of 63 patients. Thirty two patients were given 5-ASA and 31 bismuth enemas. Table III gives the concurrent treatment, sex ratios, and means and standard deviations for age, weight, duration of disease, and duration of the recent flare up; the groups were similar in most respects although there was a difference in the sex ratio.

On admission to the trial those given 5-ASA had less severe symptoms than the bismuth group although the differences in symptoms and in both sigmoidoscopic and histological grades did not achieve statistical significance (Table IV). The initial global clinical scores for symptoms were $1.7(\mathrm{SD} 0.5)$ and $1.9(\mathrm{SD} 0.4)$ respectively for the 5-ASA and bismuth groups. These differences were also reflected in the St Mark's score and grades for sigmoidoscopy and histology in the two groups (Table IV).

There was a significant improvement in all symptoms with both 5-ASA and bismuth enemas. The improvement was noted in the global clinical assessment, stool frequency, occurrence of blood, changes in stool consistency, occurrence of abdominal pain, urgency, and the patients overall assessment of general well being. The St Mark's score, change in sigmoidoscopic grading, and histology all showed significant improvement in both groups (Table IV).

The improvement in both treatment groups was compared by analysis of covariance taking into account the differences in severity of disease on entry to the trial.

The only statistically significant difference between the groups was for the presence of blood in the stool; 5-ASA patients had significantly less blood reported than the bismuth group. The presence of mucus in the stool was not analysed because the bismuth enema itself had the appearance of white mucus, which invalidated any comparison.

A comparison of patients who achieved complete symptomatic relief (global clinical grade of 0 ; defined as less than three motions per day, with formed stools, no urgency, mucus, or blood) showed 18 of 32 in the 5-ASA group compared with 12 of 31 who used bismuth $\left(\chi^{2}\right.$ $1 \cdot 94 ; \mathrm{p}=0 \cdot 16)$.

Sigmoidoscopic appearances returned to normal (grade 0 ) in 20 of 32 taking 5-ASA and 15 of 31 in the bismuth group $\left(\chi^{2} 1 \cdot 27 ; p=0 \cdot 26\right)$. Improvement by at least one histological grade in the rectal biopsy was seen in 16 of 32 who used 5 -ASA and 14 of 31 given bismuth $\left(\chi^{2} 0 \cdot 15\right.$; $p=0 \cdot 70$ ).

Among those completing the trial there were no side effects reported. Although 5-ASA enemas were easier to administer (only one patient had difficulty compared with six in the bismuth group), bismuth was easier to retain (eight patients on 5-ASA had difficulties but only two patients on bismuth).

BISMUTH CONCENTRATIONS IN SERUM SAMPLES Serum samples for measurement of bismuth were collected from 46 patients of whom 25 were in the bismuth group; only those from the bismuth group were analysed at the end of 
TABLE III Patient characteristics on entry to trial

\begin{tabular}{lll}
\hline & $\begin{array}{l}5-A S A \text { group } \\
(n=32)\end{array}$ & $\begin{array}{l}\text { Bismuth group } \\
(n=31)\end{array}$ \\
\hline Sex M:F & $12: 20$ & $5: 26$ \\
Age (y) & $42(15)$ & $41(14)$ \\
Weight (kg) & $66 \cdot 3(12 \cdot 1)$ & $64 \cdot 4(10 \cdot 6)$ \\
Duration of disease (months) & $92(86)$ & $98(94)$ \\
Duration of relapse (weeks) & $11(19)$ & $9(11)$ \\
Patients on oral prednisolone & 2 & 5 \\
Patients on oral 5-ASA & 23 & 22 \\
\hline preparations & 23 & \\
\hline
\end{tabular}

Comparison of characteristics of those patients entered into the study and analysable (32 patients in 5-ASA and 31 patients in bismuth groups). Statistical comparison shows no difference apart bismuth groups). Statistical comparison shows no difference apart from the unusual sex ratio which is most apparent in the bismuth treated group. Figures in parentheses are standard deviations. Oral 5-ASA was predominantly Asacol but seven patients had sulphasalazine and two had olsalazine.

the study. Analysis was by atomic absorption spectrophotometry. ${ }^{12}$

After two weeks of treatment median serum bismuth concentration was $3 \mathrm{ng} / \mathrm{g}$ (interquartile range 2.0 to 6.0 ) and at trial exit it was $3 \mathrm{ng} / \mathrm{g}$ (interquartile range 1.75 to $6 \cdot 25$ ).

At two weeks, however, one patient had a serum bismuth concentration well outside this range (44 ng/g); she denied use of any other bismuth medications and the concentration fell to $3 \mathrm{ng} / \mathrm{g}$ in the succeeding two weeks.

\section{Discussion}

This is the first controlled trial of a bismuth enema preparation in patients with distal ulcerative colitis. 5-Aminosalicylic acid was used as the alternative treatment because it is one of the most effective topical treatments available. ${ }^{1413}$ After four weeks there were significant improvements in symptoms as well as sigmoidoscopic and histological grades that were of a similar degree in both groups.

Every attempt was made to ensure that the trial was double blind. Although enemas did not appear identical they were only labelled with the trial number. Information about the nature of the enema was withheld from the clinician involved in assessments. The histological assessments were made without knowledge of either patient group or the order of biopsies. The improvements that occurred during treatment with both preparations were similar and did not differ statistically between the groups. The method of analysis of covariance was used to take into account the small, random differences in severity of disease between treatment groups at the commencement of the trial that arise when random allocation is used. In this respect groups did not differ statistically but the adjustment is standard practice and allows a fairer comparison. Results with 5-ASA were slightly better, although not statistically significant, than those obtained with the bismuth preparation.

An exception to this was the reporting of blood in motions, where 5-ASA was significantly better. Table IV gives a comparison of the change in scores during treatment with the two types of enema; negative values from the analysis of covariance favour the 5-ASA enema.

To establish one enema as clearly superior would have required many more patients. Because of ethical considerations no placebo group was established and it is conceded that this inevitably limits the strength of overall conclusions made. In particular, spontaneous improvement in both groups, who were recruited in exacerbation, could well occur irrespective of treatment.

The results give further support to previous pilot studies with bismuth preparations. Srivastava et $a l^{6}$ used tripotassium dicitratobismuthate equivalent to $432 \mathrm{mg}$ of metallic bismuth, neutralised to $\mathrm{pH} 7$ with a viscous solution of Keltrol given at night and found improvement in nine of 11 patients who used this enema for one month. Ryder et al $l^{5}$ used bismuth subsalicylate with a maximum dose of $928 \mathrm{mg}$ metallic bismuth as an enema in 15 patients with colitis unresponsive to conventional treatment; they found oral bismuth subsalicylate ineffective but with twice daily enemas over eight weeks symptoms improved in nine patients and sigmoidoscopy findings improved in 11 patients. The dose of bismuth in our enema was equivalent to half the recommended dose of DeNoltabs for gastric pathology (432 mg metallic bismuth). Our aim was to limit any potential toxicity from absorption and allow the possibility of doubling the dose with enemas twice daily should this be required in clinical use.

Measurements of bismuth in serum samples during the trial enabled us to monitor whether significant accumulation occurred. Median concentrations were low ( $3 \mathrm{ng} / \mathrm{g}$ serum) with narrow ranges. One patient had higher concentrations after two weeks of treatment but not at the conclusion of the trial. There was no evidence of accumulation of bismuth from the enemas. Previous work had suggested accumulation of bismuth in the body when tripotassium

TABLE IV Clinical, sigmoidoscopic, and histological assessments

\begin{tabular}{|c|c|c|c|c|c|c|}
\hline \multirow[b]{2}{*}{ Assessment } & \multicolumn{2}{|l|}{ 5-ASA enemas } & \multicolumn{2}{|l|}{ Bismuth enemas } & \multicolumn{2}{|l|}{ Analysis of covariance } \\
\hline & Mean start $(S D)$ & Mean end (SD) & Mean start $(S D)$ & Mean end (SD) & Difference $(95 \% C I)$ & p Value \\
\hline $\begin{array}{l}\text { Global clinical }(0-3) \\
\text { Stool frequency } \\
\text { Blood in stool }(0-2) \\
\text { Stool consistency }(0-2) \\
\text { Abdominal pain }(0-2) \\
\text { Urgency }(1-10) \\
\text { Wellbeing }(1-10) \\
\text { St Mark's Score }(0-22) \\
\text { Sigmoidoscopy }(0-4) \\
\text { Histology }(0-4)\end{array}$ & 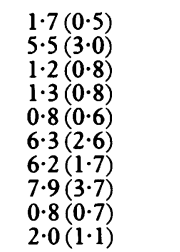 & $\begin{array}{l}0 \cdot 6(0 \cdot 8)^{\star \star \star} \\
3 \cdot 6(2 \cdot 9)^{\star \star} \\
0 \cdot 3(0 \cdot 6)^{\star \star \star} \\
0 \cdot 5(0 \cdot 7)^{\star \star \star} \\
0 \cdot 4(0 \cdot 6)^{\star \star} \\
3 \cdot 7(2 \cdot 7)^{\star \star \star} \\
7 \cdot 4(1 \cdot 6)^{\star \star \star} \\
2 \cdot 8(3 \cdot 7)^{\star \star \star} \\
0 \cdot 4(0 \cdot 6)^{\star \star} \\
1 \cdot 2(1 \cdot 1)^{\star \star \star}\end{array}$ & $\begin{array}{l}1 \cdot 9(0 \cdot 4) \\
5 \cdot 7(3 \cdot 1) \\
1 \cdot 5(0 \cdot 7) \\
1 \cdot 3(0 \cdot 7) \\
0 \cdot 9(0 \cdot 7) \\
6 \cdot 3(2 \cdot 8) \\
6 \cdot 0(1 \cdot 5) \\
8 \cdot 6(2 \cdot 6) \\
1 \cdot 0(0 \cdot 6) \\
2 \cdot 3(1 \cdot 1)\end{array}$ & $\begin{array}{l}0.9(0.9)^{\star \star \star} \\
3 \cdot 7(2 \cdot 6)^{\star \star} \\
0 \cdot 9(0 \cdot 8)^{\star \star} \\
0 \cdot 5(0 \cdot 6)^{\star \star \star} \\
0 \cdot 5(0 \cdot 7)^{\star \star} \\
3 \cdot 3(2 \cdot 7)^{\star \star \star} \\
7 \cdot 5(1 \cdot 5)^{\star \star \star} \\
3 \cdot 7(3 \cdot 3)^{\star \star \star} \\
0 \cdot 5(0 \cdot 6)^{\star \star \star} \\
1 \cdot 7(1 \cdot 0)^{\star}\end{array}$ & $\begin{array}{l}-0.25(-0.70 \text { to }+0.20) \\
-0.10(-1.32 \text { to }+1.12) \\
-0.49(-0.90 \text { to }-0.11) \\
+0.02(-0.32 \text { to }+0.30) \\
-0.10(-0.40 \text { to }+0.20) \\
+0.40(-0.96 \text { to }+1.76) \\
-0.10(-0.90 \text { to }+0.70) \\
-0.64(-2.40 \text { to }+1.12) \\
-0.11(-0.39 \text { to }+0.17) \\
-0.42(-0.92 \text { to }+0.08)\end{array}$ & $\begin{array}{l}0.27 \\
0.87 \\
0.01 \\
0.91 \\
0.49 \\
0.56 \\
0.81 \\
0.47 \\
0.42 \\
0.11\end{array}$ \\
\hline
\end{tabular}


dicitratobismuthate was taken orally, ${ }^{14} 15$ although this has been disputed. ${ }^{16}$ Our own unpublished data on absorption from these enemas indicates that less than $0.02 \%$ of administered bismuth is absorbed. This, and the quoted safe level for serum bismuth (10-50 $\mu \mathrm{g} / \mathrm{l})^{17}$ reassures us of the low toxic potential for this enema.

The authors of both previous pilot studies of bismuth in colitis were prompted to use the heavy metal because of previous reports of benefit with arsenical compounds. ${ }^{18} 19$ Bismuth has also become popular in recent years as a treatment in peptic ulcer to eradicate Helicobacter pylori. It has been used for many years in traveller's diarrhoea, as a colostomy deodoriser, and as an antispirochetal agent in syphilis. ${ }^{17} 20$

The carbomer $934 \mathrm{P}$ is a synthetic polyacrylate characterised by multiple side chains of carboxyl groups. In the pharmaceutical industry it is used as a suspending agent for liquids and as a binder in tablets. It has been shown to promote gel formation with mucin monomers from both gastric and colonic mucus. ${ }^{21}$ In the colon it also inhibits faecal protease activity, which is responsible for mucolysis and solubilisation of the adherent layer of mucus gel. We found that bismuth compounds, both citrate and subsalicylate, formed soluble complexes with the carbomer and at $\mathrm{pH} 6.4$ to 7.5 produced a viscous mucus-like solution that was convenient to administer and retain as an emena. We used carbomer primarily as a vehicle for the bismuth to try to achieve adherence to the surface mucosa with optimal topical application of the bismuth. In ulcerative colitis the adherent visible layer of mucus is absent from actively inflamed areas - a feature that does not apply in Crohns disease. ${ }^{22}$

The nature of any factors within the colonic lumen that may be responsible for either the initiation or continuation of inflammation remains unknown but recent attention has focused on the possible role of flora associated with the mucosa. ${ }^{23}$ Support for this comes from the finding that faecal protease activity, largely derived from bacteria, is increased threefold in colitis. ${ }^{24}$ Because bismuth is known to have a toxic effect on some microorganisms its therapeutic benefit in colitis may be related to this. ${ }^{25}$ Whether loss of the adherent mucus is related to anaerobic flora associated with the mucosa is an interesting possibility. An alternative might be interference with bacterial adhesion by pathogenic Escherichia coli, which have abnormal adherence in ulcerative colitis. ${ }^{26}$ Bismuth, because of its effects on enzyme systems in bacteria, may have a therapeutic effect in colitis through this mechanism. The carbomer 934P may also have an effect, however, because it inhibits faecal protease activity and facilitates the formation of a viscous gel in vitro. ${ }^{21}$ The possibility that the complex may be effective by all of these mechanisms cannot be excluded. The relative contribution of each component cannot be clarified from this study.

Our findings suggest that bismuth citrate complexed with carbomer $934 \mathrm{P}$ is of therapeutic benefit in left sided ulcerative colitis with results that do not differ significantly from those obtained from 5-ASA enemas. It may act by a novel mechanism and offers a further therapeutic possibility for those who are intolerant of aminosalicylates.

We gratefully acknowledge help from Miss Bel Adamson in the Pharmacy Department, University Hospital of Wales; Tillotts acid enemas and Rooney Laboratories, Basingstoke, UK performed assays of serum bismuth. Dr Robert Newcombe, Senior Lecturer, Department of Medical Computing and Statistics, University of Wales College of Medicine, Cardiff gave helpful statistical advice. This study was approved by ethics committees at each of the participating hospitals with every patient giving written, informed consen

1 Sutherland LR, Martin F, Greer S, Robinson M, Greenberger N, Saibil F, Martin T, Sparr J, Prokipchuk E, Borgen L 5aminosalicylic acid enema in the treatment of distal ulcerative colitis, proctosigmoiditis and proctitis. Gastroenterology 1987; 92: 1894-8.

2 Willoughby CP, Campieri M, Lanfranchi G, Truelove SC, Jewell DP. 5-aminosalicylic (Pentasa) in enema form for the treatment of active ulcerative colitis. Italian fournal of Gastroenterology 1986; 18: 15-7.

3 Danish 5-ASA Group. Topical 5-ASA versus prednisolone in ulcerative proctosigmoiditis: A randomised, double-blind multicenter trial. Dig Dis Sci 1987; 32 (6): 598-602.

4 Campieri M, Lanfranchi GA, Bazzocchi G, Brignola C, Sarti F, Franzin G, Battocchia A, Labo G, Dal Monte PR. Treatment of ulcerative colitis with high doses 5-ASA Treatment of ulcerative colitis

5 Ryder SD, Walker RJ, Jones J, Rhodes JM. Rectal bismuth subsalicylate as therapy for ulcerative colitis. Aliment Pharmacol Therap 1990; 4: 333-8.

6 Srivastava ED, Swift GL, Wilkinson S, Williams GT, Evans BK, Rhodes J. Tripotassium dicitrato bismutriate enemas in the treatment of ulcerative proctitis. Aliment Pharmacol Therap 1990; 4: 577-8.

7 Powell-Tuck J, Lennard-Jones JF, May CS, Wilson CG, Paterson JW. Plasma prednisolone levels after administration of prednisolone 21-phosphate as a retention enema in colitis. BMF 1976; 1: 193-5.

8 Powell-Tuck J, Day DW, Buckell NA, Wadsworth J, Lennard-Jones JE. Correlation between sigmoidoscopic appearances and other measures of disease activity in appearances and other measures of disease

9 Truelove SC, Witts LJ. Cortisone in ulcerative colitis: Final Report on a therapeutic trial. BMF 1955; 2: 1041-8.

10 Baron JH, Connell AM, Lennard-Jones JE. Variation between observers in describing mucosal appearances in proctocolitis. $B M F$ 1964; $1: 89-92$.

11 Truelove SC, Richard WCS. Biopsy studies in ulcerative colitis. $B M \mathcal{F}$ 1956; 2: 1315-21.

12 Rooney RC. Determination of bismuth in blood and urine. Analyst 1976; 101: 749-52.

13 Campieri M, de Franchis R, Bianchi Porro G, Ranzi T, Brunetti G, Barbara L. Mesalazine (5-ASA) suppositories in the treatment of ulcerative proctitis or distal proctosigthe treatment of ulcerative proctitis or distal proctosig-
moiditis. A randomised, controlled trial. Scand $\mathcal{F}$ Gaiditis. A randomised,

14 Gavey CJ, Szero ML, Nwokolo CU, Sercombe J, Pounder RE. Bismuth accumulates in the body during treatment with tripotassium dicitrato bismuthate. Aliment Pharmacol Therap 1989; 3: 21-8.

15 Nwokolo CU, Gavey CJ, Smith JTL, Pounder RE. Absorption of bismuth from oral doses of tripotassium dicitrato bismuth. Aliment Pharmacol Therap 1989; 3: 29-39.

16 Benet LZ. Safety and pharmacokinetics: colloidal bismuth subcitrate. Scand $\mathcal{f}$ Gastroenterol 1991; 26 (suppl 185): 29-35

17 Marshall BJ. The use of bismuth in gastroenterology. Am $\mathcal{F}$ Gastroenterol 1991; 86: 16-25.

18 Connell AM, Lennard-Jones JE, Misiewicz JJ, Baron JH, Avery Jones F. Comparison of acetarsol and prednisolone21-phosphate suppositories in the treatment of idiopathic proctitis. Lancet 1965; i: 238-39.

19 Forbes A, Brotton TC, House IM, Gazzard BG. Safety and efficacy of acetarsol suppositories in unresponsive proctitis. Aliment Pharmacol Therap 1989; 3: 553-6.

20 Gorbach SL. Bismuth therapy in GI diseases. Gastroenterology 1990; 99: 863-75.

21 Hutton DA, Pearson JP, Allen A, Foster SNE. Mucolysis of the colonic mucus barrier by faecal proteinases: inhibition by interacting polyacrylate. Clin Sci 1990; 78: 265-71.

22 Pullan RD, Rhodes M, Allen A, Rhodes J. Adherent layer of colonic mucus in man: measurement of thickness and its relevance to mucosal protection and inflammatory bowel relevance to mucosal protection
disease. Br f Surg 1992; 79: 1229 .

23 Hartley MG, Hudson MJ, Swarbrick ET, Hill MJ, Gent AE, Hellier MD, Grace RH. The rectal mucosa-associated Hellier MD, Grace RH. The rectal mucosa-associated
microflora in patients with ulcerative colitis. $\mathcal{F}$ Med Microbiol 1992; 36: 96-103.

24 Samson HJ, Allen A, Pearson JP, Cunliffe WJ, Rhodes M, Rhodes J. Faecal proteinase activity; raised values in patients with ulcerative colitis. Gut 1991; 32: A1235-6.

25 Lee SP. The mode of action of colloidal bismuth subcitrate. Scand $\mathcal{F}$ Gastroenterol 1991185 (suppl): 1-6.

26 Burke DA, Axon ATR. Adhesive Escherichia coli in inflammatory bowel disease and infective diarrhoea. BMF 1988; 297 ; 102-4. 